\title{
Analysis of Android-based Body Health Monitoring System Results using Fuzzy Mamdani Method
}

\author{
Ade Silvia Handayani ${ }^{1, *}$ Ahmad Taqwa ${ }^{1}$ Irawan Hadi $^{1}$ Martinus Mujur Rose ${ }^{1}$ \\ Nyayu Latifah Husni ${ }^{1}$ Sopian Soim ${ }^{1}$ Sanyyah Plowerita ${ }^{1}$ \\ ${ }^{1}$ Department of Electrical Engineering, Politeknik Negeri Sriwijaya, Palembang, Indonesia \\ ${ }^{*}$ Corresponding author. Email: ade_silvia@polsri.ac.id
}

\begin{abstract}
In a health monitoring system, an Android-based Health Detector (AHD) application uses fuzzy Mamdani to detect health concerns. The data given can be used as an input for multi-sensor readings produced from physiological health detection. The body's total health is determined when the detected health is merged with the fuzzy Mamdani algorithm. Anger, apathy, and apathy were calculated as variables. The fuzzy Mamdani method to body health problems involves creating fuzzy sets, applying implications functions, and synthesizing rules. This study found that aging affects both men's and women's health. Persons over 65 are more likely than younger people to suffer health issues, even if only a minority of them have been diagnosed. The fuzzy Mamdani technique had a high accuracy rate of 93.33 percent in this study.
\end{abstract}

Keywords: Algorithm, Body Health, Fuzzy Mamdani, and Health Detection

\section{INTRODUCTION}

In the era of the Covid-19 pandemic, one of the most important things for humans is health. Determination of health is done by monitoring heart rate, body temperature, blood pressure, and oxygen levels in the blood would help to establish an individual health baseline and alert users of abnormalities indicating that further medical attention [1].

Generally, the determination of health is carried out by medical personnel and smart support equipment. Given the track record of information from the WHO (World Health Organization) has more than 1.7 million cases of Covid-19 worldwide [2], this requires technology that can monitor patients without physical contact. Several technologies have been developed for health monitoring, such as WSN (Wireless Sensor Network) [3], WBAN (Wireless Body Area Network), and IWBN (Implanted Wireless Body Area Network) [4].

WBAN is a branch of WSN which is related to sensors installed on the human body [5]. Wireless Body Area Network technology through the use of wireless sensors on the body provides a remote and real-time health monitoring system. By building a body health monitoring system using WBAN technology based on android. It is hoped that the health condition of the body can be monitored directly for both medical personnel.

Health monitoring is less effective without determining health conditions. Determination of health conditions is useful for providing information on health conditions and as a guide in taking medical action. In this study, the implementation of the fuzzy Mamdani method will be carried out on the results of a body health monitoring system that utilizes Artificial Intelligence (AI) technology.

One of the fields that use artificial intelligence is fuzzy logic. Fuzzy logic is a way to map problems from input to expected output. Fuzzy logic is used to translate a scale by using language (linguistic) and can cultivate uncertainly so that it quickly decides a human reason. One method of fuzzy logic technique is the fuzzy Mamdani method [6].

In paper [6] the fuzzy Mamdani method was successfully applied to diagnose cataract eye disease with input in the form of cataract eye disease symptoms and output in the form of cataract eye disease. The results of testing the accuracy of the expert system for diagnosing 
cataract eye disease with the fuzzy Mamdani method are $78 \%$. Similar to paper [7] the fuzzy Mamdani method has also been successfully implemented to diagnose cancer risk and has achieved $81 \%$ success with the system.

From the studies above, the fuzzy Mamdani method is able to make decisions or conclusions. In this case, the fuzzy Mamdani method is applied to determine the health condition of the body from the results of health monitoring.

\section{LITERATURE REVIEW}

\subsection{Body Health Condition}

The condition of the body's health is to state the state of a person's body. According to medical Journal BMJ [8], health according to the World Health Organization (WHO) is a state of complate physical, mental, and social well-being and not marely the absence of disease or infirmity. Determination of health can be done by checking or monitoring vital signs. Based on the monitoring of vital signs, the value of the monitoring results obtained must be within the recommended range so as not to require medical action.

The action referred to in the context of the doctorpatient relationship can be narrowed down to nonpharmacological therapy for the patient. Most of the medical procedures are part of the surgical field. For other medical terms, namely indications, indications are conditions that cause a therapy, action, or investigation to be carried out. The indication can also be a sign that leads to a specific clinical conclusion or diagnosis.

\subsection{Checking or Monitoring Vital Signs}

Examination or monitoring of vital signs is a measurement of the most basic body functions carried out to find out clinical signs and is useful for strengthening the diagnosis of a disease. Vital signs in the body can be said as a benchmark to see the general health condition. Heart rate, body temperature, blood pressure, and blood oxygen levels are vital signs that are routinely checked and monitored.

\subsubsection{Age}

Age refers to the number of completed years between a person's date of birth and the reference date [9]. The following age categories according to the Indonesian Ministry of Health (2009):
Table 1. Age Category

\begin{tabular}{|c|c|}
\hline Age Category & Year Range \\
\hline Early Adolescence & $12-16$ \\
\hline Late Adolescence & $17-25$ \\
\hline Early Adulthood & $26-35$ \\
\hline Late Adulthood & $36-45$ \\
\hline Early Old Age & $46-55$ \\
\hline Late Old Age & $56-65$ \\
\hline Old Age & $>60$ \\
\hline
\end{tabular}

\subsubsection{Gender}

Gender affects heart rate, body, temperature and blood pressure. Gender also effect heart rate. In addition, available reports are controversial, with some reporting a higher HRV for female than for male subjects and others reporting the converse [10]. Wunderlich declared that women might have higher normal body temperature than men,but other invest threetors had found the opposite. No study with strong or fairly strong evidence reported axillary temperature by gender pared with the definition of today [11]. Recent studies have shown that blood pressure is higher in men than in women at similar ages. After menopause, however, blood pressure increases in women to levels even higher than in men [12].

\subsubsection{Heart Rate}

The heart rate (HR) or pulse is the frequency of cardiac cycles, expressed as beats per minute (bpm). The HR changes according to the body's need and is susceptible to alteration in the body's normal state [1] The normal heart rate range for adults who do not have health problems is $60-100$ beats per minute [13]. Measurement of human heart rate based on age can be seen in the following table.

Table 2. Number of Heartbeats Per Minute by Age

\begin{tabular}{|c|c|c|c|}
\hline Age & $\begin{array}{c}\text { Min } \\
(\mathbf{b p m})\end{array}$ & Max (bpm) & $\begin{array}{c}\text { Average } \\
(\mathbf{b p m})\end{array}$ \\
\hline $\begin{array}{c}6 \text { years }-12 \\
\text { years }\end{array}$ & 65 & 100 & 83 \\
\hline $\begin{array}{c}12 \text { years }-18 \\
\text { years }\end{array}$ & 60 & 90 & 85 \\
\hline $\begin{array}{c}19 \text { years }-69 \\
\text { years }\end{array}$ & 60 & 100 & 80 \\
\hline$>70$ years old & 60 & 100 & 80 \\
\hline
\end{tabular}




\subsubsection{Body Temperature}

Body temperature provides insight into a person's physiological state. Elevated body temperature is indicative of fever and decreased body temperature is indicative of low blood flow due to circulatory shock [1]. The normal body temperature range for adults who do not have health problems is $36.3-37.3{ }^{\circ} \mathrm{C}$ [13]. Measurement of human body temperature by age can be seen in Table 2.

Table 3. Human Body Temperature Based on Age

\begin{tabular}{|c|c|c|c|}
\hline Age & $\begin{array}{c}\text { Min } \\
\left({ }^{\circ} \mathrm{C}\right)\end{array}$ & $\operatorname{Max}\left({ }^{\circ} \mathrm{C}\right)$ & $\begin{array}{c}\text { Average } \\
\left({ }^{\circ} \mathrm{C}\right)\end{array}$ \\
\hline 6 years - 12 years & 37 & 37 & 37 \\
\hline 12 years - 18 years & 36,1 & 37 & 37 \\
\hline 19 years - 69 years & 36,1 & 37,2 & 36,65 \\
\hline$>70$ years old & 35 & 37,2 & 37,2 \\
\hline
\end{tabular}

\subsubsection{Blood Pressure}

Blood pressure is one of the most important signs of a person's general health. The two most significant numbers in blood pressure are the maxima (systolic) and minima (diastolic). The typical blood pressure measuring device is the sphygmomanometer. A healthy person's blood pressure is below 120/80 (systolic/diastolic), higher blood pressure was diagnosed as hypertension [1]. Measuring human blood pressure by age can be seen in table 4.

Table 4. Blood Pressure by Age

\begin{tabular}{|c|c|c|}
\hline Age & $\begin{array}{c}\text { Systole } \\
(\mathbf{m m H g})\end{array}$ & $\begin{array}{c}\text { Diastole } \\
(\mathbf{m m H g})\end{array}$ \\
\hline 6 years -12 years & $110-110$ & $60-70$ \\
\hline 12 years -18 years & $110-120$ & $60-65$ \\
\hline 19 years -69 years & $110-140$ & $60-90$ \\
\hline$>70$ years old & $120-140$ & $70-90$ \\
\hline
\end{tabular}

\subsubsection{Oxygen Levels in The Blood or Oxygen Saturation}

Oxygen saturation or oxygenation is the concentration of oxyhemoglobin in the blood divided by the sum of the concentration of oxy- and deoxyhemoglobin in the blood. In a healthy adult, pulse oxygenation should be at least $95 \%$ [1].
Table 5. Oxygen Saturation

\begin{tabular}{|c|c|}
\hline Normal & $95-100 \%$ \\
\hline Low & $<95 \%$ \\
\hline
\end{tabular}

\subsection{Wireless Body Area Network (WBAN)}

Current wireless communication technology can be used for monitoring certain parameters as in the wireless sensor network (WSN) which consists of a collection of sensors that transmit data through radio wave media. One branch of WSN that is specifically related to sensors that are installed inside, on the surface, or worn by humans is the wireless body area network (WBAN) [5].

Sensors that can transmit data wirelessly are installed to improve various health services and also improve the quality of life [14]. This technology is called a wireless body area network (WBAN). To monitor vital signs in the body, WBAN is structured in an architecture consisting of nodes, microcontroller chips, wireless communication modules, and data communication devices connected to certain networks. Figure 1 below is an illustration of the WBAN architecture [15].

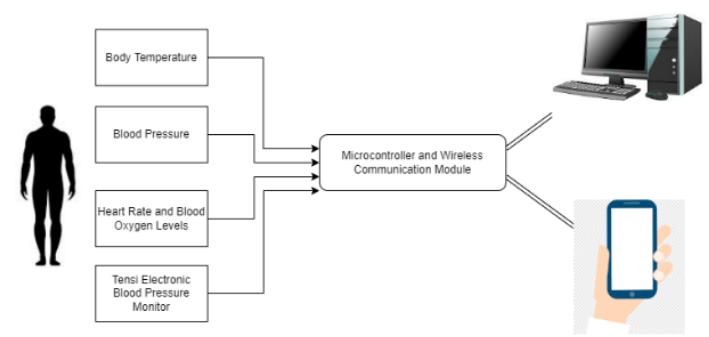

Figure 1 Architecture Wireless Body Area Network

\subsection{Android-Based WBAN Monitoring System}

Wireless Body Area Network (WBAN) technology is closely related to the development of the Internet of Things (IoT), where various digital communication devices are connected to an internet network so that data exchange becomes much easier to do with such a wide application [16]. The WBAN monitoring system has the potential to provide remote health monitoring services, fitness programs, diagnosis of chronic diseases, and so on. In addition, the current rapid development of smartphones also supports the growth of health-related wireless sensor network applications. Smartphones have many operating systems, one of which is Android..

\subsection{Fuzzy Mamdani Method}

The fuzzy Mamdani method is one part of the fuzzy inference system that is useful for drawing conclusions or the best decision in uncertain problems. The fuzzy Mamdani method in the process uses linguistic methods, 
making it easier to understand. The decision-making process using the fuzzy Mamdani method to obtain the best decision is carried out through several stages, namely the formation of fuzzy sets, application of implication functions, the composition of rules, and defuzzification [6].

\section{RESEARCH METHODOLOGY}

This study divided the design into two parts, namely hardware design and software design.

\subsection{Hardware Design}

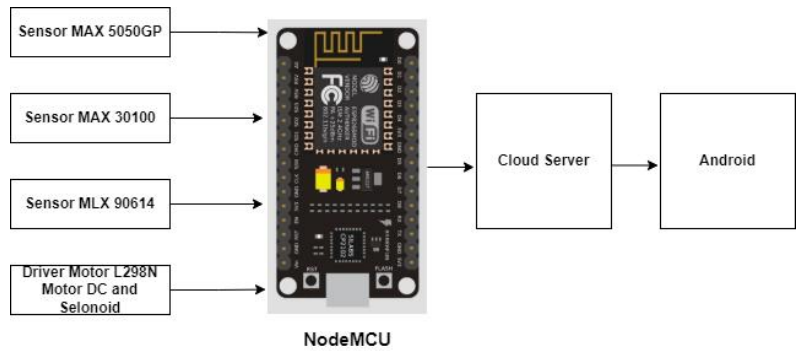

Figure 2 Block Diagram Hardware Systems

Figure 2, the body health monitoring system is designed using a NodeMCU microcontroller equipped with ESP 8266 as a wifi module in it which is used for data processing which is equipped with a MAX 5050GP sensor as a blood pressure sensor, a MAX 30100 sensor, namely a heart rate sensor and blood oxygen levels. In addition, it also uses the MLX 90614 sensor as a body temperature sensor, a DC motor is used to pump air pressure, a solenoid as a lock or hold the valve and air exhaust, and also a DC motor driver, L298N as a driver for DC motors and solenoids to the NodeMCU. After getting sensor reading data, the NodeMCU ESP8266 which is connected to wifi will send data to the server as a database and sent it in real-time. Then Android will display the results of reading sensor data.

Overall system performance in this test, sensors and other components will automatically work to detect body health by displaying information on body temperature, blood pressure, heart rate, and oxygen levels in the blood as well as providing emergency messages about the state of the body (healthy, indications, and need action).

\subsection{Software Design}

The design of the software that is made is very important in terms of the mathematical processing of the entire program. The monitoring system is designed to be able to detect the measurement value of vital signs from a person's body so that the sensor reading value is obtained in real-time.
Software design is the design of the workflow system using the fuzzy Mamdani method in the form of determining the health condition of the body from the sensor readings. The design of the software in this system includes the design of determining health conditions using the fuzzy Mamdani method to determine the health condition of the body based on three parameters, namely Healthy, Indications and Needs Action.

\subsection{Data Processing}

After going through the stages of hardware design and software design, the next stage is the data processing process. The application of the fuzzy Mamdani method for data processing in this system is started from the input, and output. On the input there are seven inputs consisting of age, gender, body temperature readings, systolic and diastolic blood pressure, heart rate, and oxygen levels in the blood. Then it produces three outputs in the form of determining the condition of the body's health, namely Healthy, Indications, and Needs Action. Through WBAN technology, wireless sensors placed on the body will detect measurements of vital signs. After the sensor has been detected and sent to the android, it will get information in the form of body health monitoring data results where the data is processed first before determining the health condition.

This data processing is carried out by the fuzzy Mamdani method, where the fuzzy Mamdani is found on android. Data processing is carried out using Android Studio programming which is governed by all commands to classify the body's health conditions (Healthy, Indications, and Need Action). So, the datas is processed on Android, then Android will read the datas by following per under with the orders that have been regulated therein and then determines the results of the body health monitoring data including determining which health conditions.

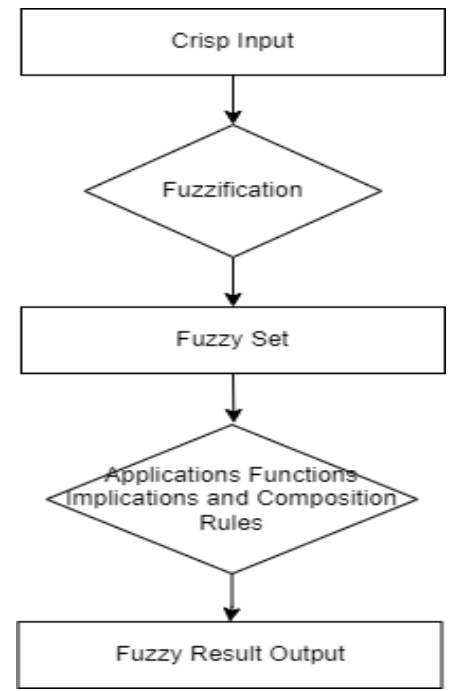

Figure 3 Fuzzy Mandani Method Process Flowchart 


\subsubsection{Stages of The Fuzzy Mamdani Method}

In determining health conditions, the fuzzy Mamdani method is used to determine the health condition of a person's body based on inputs in the form of age, gender, heart rate, body temperature, systolic blood pressure, diastolic blood pressure, and blood oxygen levels. To get the output, namely determining the condition of the body's health, three stages are needed, namely:

\section{- Formation Of a Fuzzy Set or Known as The Fuzzification}

In fuzzy Mamdani Method, the variables are divided into one or more fuzzy sets. The fuzzy variables are divided into seven variables, namely age, gender, heart rate, body temperature, systolic blood pressure, diastolic blood pressure, and blood oxygen levels. The variables used in this study are shown in table 6 .

Table 6. The Conversation Universe For Each Fuzzy Variable

\begin{tabular}{|c|c|}
\hline Fuzzy Variable & $\begin{array}{c}\text { Universe of } \\
\text { Conversation }\end{array}$ \\
\hline Age & {$[12,90]$} \\
\hline Gender & {$[0,1]$} \\
\hline Heart rate & {$[0,120]$} \\
\hline Body temperature & {$[0,40]$} \\
\hline Systolic Blood Pressure & {$[0,160]$} \\
\hline Diastolic Blood Pressure & {$[0,100]$} \\
\hline Oxygen Levels in the Blood & {$[0,100]$} \\
\hline
\end{tabular}

\section{- Implication Function App}

The second stage of the fuzzy Mamdani method is the application of the implication function. The implication function is useful for knowing the relationship between the premises and the conclusion. The form of this implication function is the statement IF $\mathrm{X}$ is A THEN $\mathrm{Y}$ is $\mathrm{B}$, where $\mathrm{X}$ and $\mathrm{Y}$ are scalars, and $\mathrm{A}$ and $B$ are fuzzy sets. In terms of fuzzy logic, propositions following IF are called antecedents, while propositions following THEN are called consequent. This fuzzy proposition or rule can be extended by using a fuzzy AND link (intersection).

Based on the input variables used, the following rules can be formed which consist of 1728 rules:

[Rule 1]: If you are young, male sex, weak heart rate, cold body temperature, low systolic blood pressure, low diastolic blood pressure, and low blood oxygen level then the body's health condition status needs action.
[Rule 1728]: If old age, female gender, fast heart rate, hot body temperature, high systolic blood pressure, high diastolic blood pressure, and normal blood oxygen levels, the health status of the body requires action.

\subsection{Composition Rules}

The third stage of the fuzzy Mamdani method is the composition of the rules. In this third stage, a procedure to determine the inference of the set and the correlation between rules uses the Max method. The fuzzy set solution is obtained by taking the maximum value from the rule output.

$\mu_{s f}(x)$

$=\max \left(\min \_s e h a t, \max \left(\min \_\right.\right.$indikasi, $\min \_b u t u h$ tindakan $\left.)\right)$

With $\mu_{s f}(x)$ stating the results of the fuzzy set, namely the health condition of the body, min_sehat stating the minimum healthy value obtained from the output of the rule, min_indication stating the minimum value of the indication obtained from the output of the rule, and min_needing action which states the minimum value of requiring action obtained from the output of the rule.

Defuzzification in this study is not used, the results of determining the health condition of the body are in the form of fuzzy sets.

\section{RESULT AND DISCUSSION}

\subsection{Body Health Monitoring System Design Results}

The system design results are divided into hardware design and monitoring system software. The results of the hardware design made in the form of a body health monitoring system, while the results of the software design were made in the form of a health condition determination page on the android application.

\subsection{Hardware Design}

The hardware design of the body health monitoring system uses three sensors, one L298N module, DC motor, solenoid, and NodeMCU microcontroller which has been successfully made according to the illustration of the tool design. The hardware (hardware) of the body health monitoring system is placed in a small box or box to avoid the risk of damage so that the tool will still work optimally. The following are the results that have been achieved in the manufacture of hardware (hardware). 


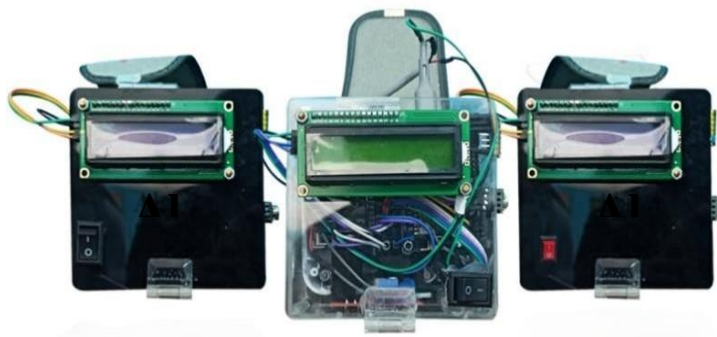

Figure 4 Outside of Hardware Display

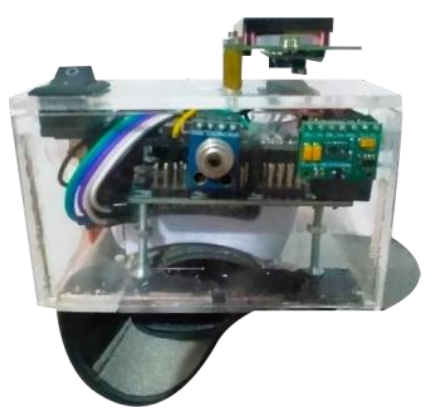

Figure 5 Side of Hardware Display

The hardware in this air quality monitoring system is placed in a box to reduce the risk of damage. It continues to work optimally in conditions of the data collection process. It makes it easier to find the location of the tool with location information in latitude and longitude.

\subsection{Software Design}

From the tests that have been carried out, the results obtained that the software is an Application Of Health Detector (AHD) application that has included the fuzzy Mamdani method to determine the health condition of the body. Here is the source coding of the stages of the fuzzy Mamdani method on the android studio:

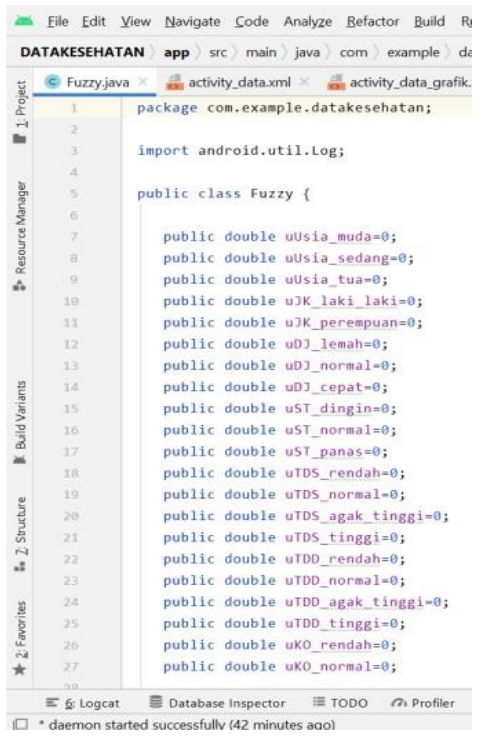

Figure 6 Fuzzy Mamdani Method Source Coding
In Figure 6, the source coding of the fuzzy Mamdani method for the fuzzification stage uses the Java programming language. At this stage of fuzzification of the input variables, namely the results of sensor readings, the formation of a fuzzy set. Furthermore, the membership function of each fuzzy set is determined by input variables as shown in Figure 7 as follows. Figure 7 is source coding for one example of calculating the membership function for young and middle age groups.

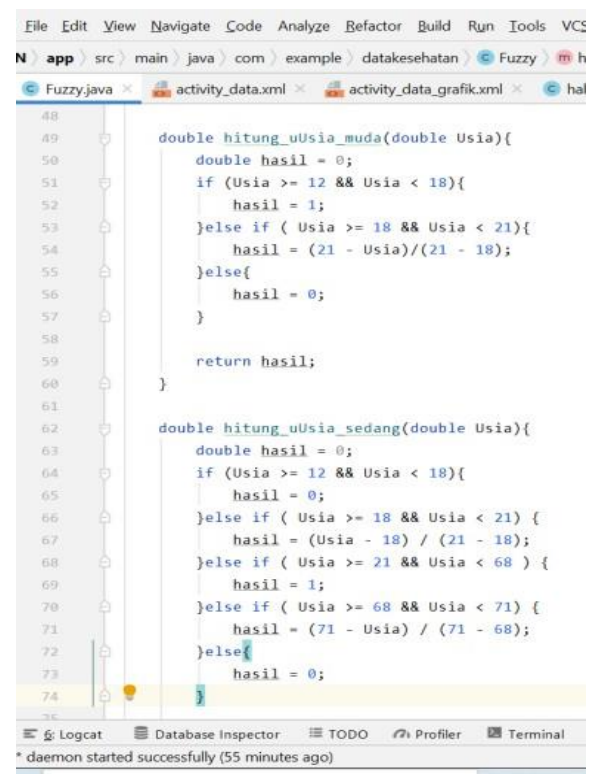

Figure 7 Source coding in determining membership functions

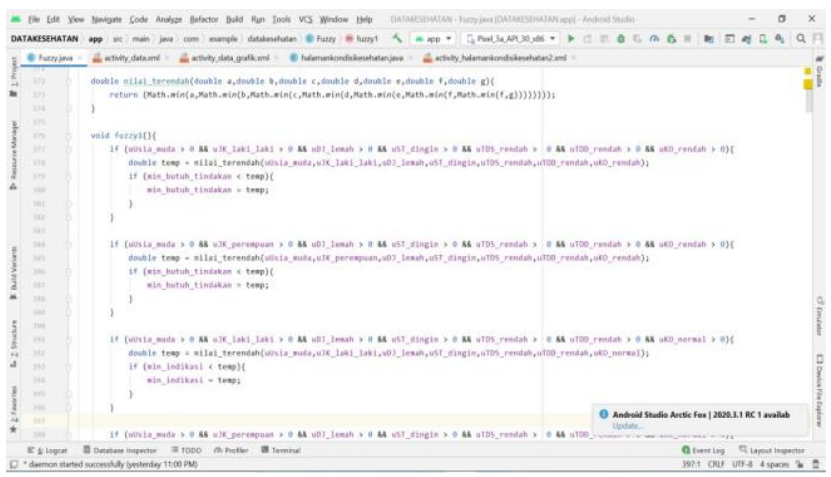

Figure 8 Source coding Application Stage Function Implication

In Figure 8, the source coding stages of the implication function application use the Java programming language. At this stage, the formation of a proposition or fuzzy rule, the fuzzy rules formed are 1728 rules. However, because too many rules will make the source code too long, so it is divided into 11 groups of rules with 160 rules in each group. After the proposition is formed, the next step is to determine the membership 
value based on the fuzzy rules that have been formed using the Min implication function.

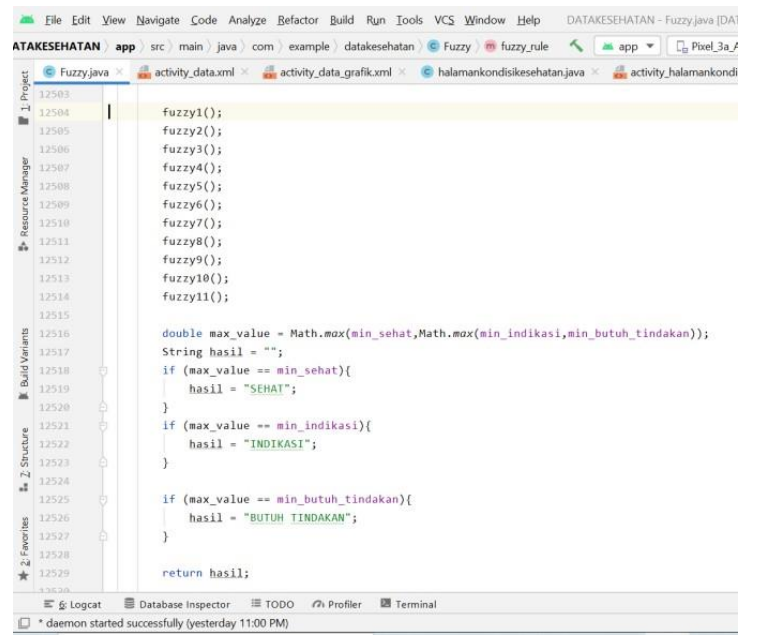

Figure 9 Source coding Stages Composition Rules

In Figure 9 the source coding for the rule composition stage is the last stage of the fuzzy Mamdani method. At this stage, determining the fuzzy set solution is obtained by taking the maximum value from the output rules using the Max method. The fuzzy set results obtained are the determination of health conditions. And the following is the source code of the health condition page on the android studio:

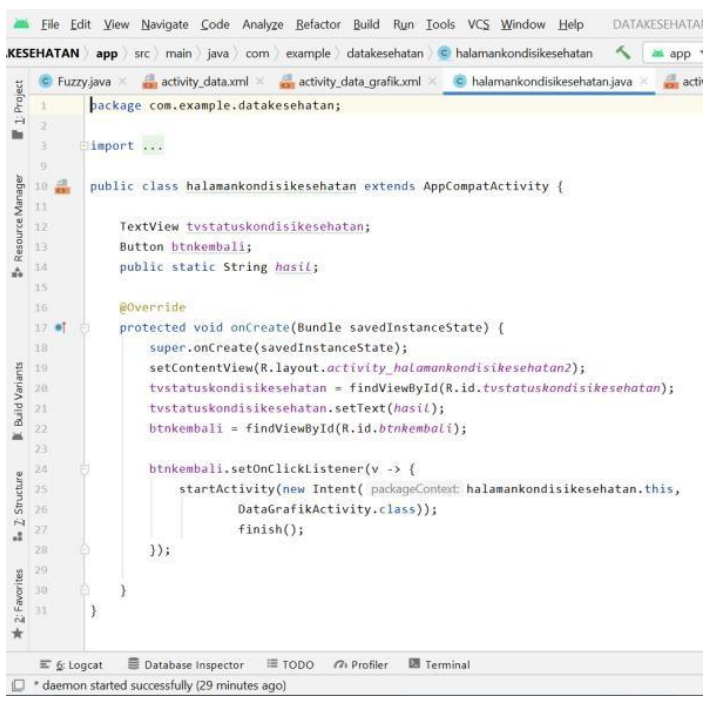

Figure 10 Source coding Health Conditions Page View

In Figure 10, the source coding of the health condition page display uses the XML markup language and the Java programming language. On this health condition page, it will display the determination of the body's health condition which is divided into three parameters, namely Healthy, Indications, and Need Action.
Accuracy $(\%)=$ Number Of Matching Data x 100\%

$$
\begin{aligned}
& \text { Amount Whole Data } \\
= & \frac{84}{90} \times 100 \% \\
= & 93,33 \%
\end{aligned}
$$

From the above calculation, it can be concluded that the accuracy of the fuzzy Mamdani method in determining body health conditions is $93.33 \%$.

\section{CONCLUSION}

The fuzzy Mamdani approach has been successful in determining the body's health condition. Monitored outcomes included heart rate, body temperature, blood pressure, and oxygen levels. Seven fuzzy variables result in 1728 fuzzy rules. These numerous regulations can generate problems in establishing rules and determining health conditions. The monitoring data revealed that age influences health parameters. Older folks often have health issues that require attention. Adult age dominant has a healthy health status, as well as the adolescent age. In testing, 30 data for tool 1, 30 for tool 2, 30 for tool 3 3. Using fuzzy Mamdani, the performance accuracy of diagnosing health problems is 93.33 percent.

\section{REFERENCES}

[1] Y. Khan, A. E. Ostfeld, C. M. Lochner, A. Pierre, and A. C. Arias, "Monitoring of Vital Signs with Flexible and Wearable Medical Devices," $A d v$. Mater., vol. 28, no. 22, pp. 4373-4395, 2016, doi: 10.1002/adma.201504366.

[2] S. Raed and A. S. Alabady, "A Review on Energy Efficient Routing Protocols in Wireless Body Area Networks (WBAN) for Healthcare," Int. J. Appl. Eng. Res., vol. 10, no. 10, 2020.

[3] M. N. O. Sadiku, K. G. Eze, S. M. Musa, R. G. Perry, P. V. A, and P. View, "Wireless Sensor Networks for Healthcare Available online www.jsaer.com Journal of Scientific and Engineering Research , 2018, 5 ( 7 ): 210-213 Wireless Sensor Networks for Healthcare," no. September, pp. 3-7, 2018.

[4] J. Ahmad and F. Zafar, "Journal of Technology Review of Body Area Network Technology \& Wireless Medical Monitoring," vol. 2, no. 2, pp. 186-188, 2012, [Online]. Available: http://www.esjournals.org.

[5] P. A. Kiran, "A Review on Wireless body area network," Int. J. Sci. Eng. Res., vol. 3, no. 6, pp. 72-75, 2015.

[6] A. Rose and W. I. D. Rae, "Expert System Diagnosis of Cataract Eyes Using Fuzzy 
Mamdani Method Expert System Diagnosis of Cataract Eyes Using Fuzzy Mamdani Method," 2018.

[7] A. Yilmaz, K. Ayan, and E. Adak, "Risk analysis in cancer disease by using fuzzy logic," Аппи. Conf. North Am. Fuzzy Inf. Process. Soc. NAFIPS, 2011, doi: 10.1109/NAFIPS.2011.5752012.

[8] M. Huber et al., "How should we define health?," $B M J$, vol. 343, no. 7817, pp. 1-3, 2011, doi: 10.1136/bmj.d4163.

[9] Singapore Department of Statistics, "National Statistical Standards," Recomm. Defin. Classif. Age, pp. 1-3, 2015.

[10] K. Umetani, D. H. Singer, R. McCraty, and M. Atkinson, "Twenty-four hour time domain heart rate variability and heart rate: Relations to age and gender over nine decades," J. Am. Coll. Cardiol., vol. 31, no. 3, pp. 593-601, 1998, doi: 10.1016/S0735-1097(97)00554-8.

[11] M. Sund-Levander, C. Forsberg, and L. K. Wahren, "Normal oral, rectal, tympanic and axillary body temperature in adult men and women: A systematic literature review," Scand. J. Caring Sci., vol. 16, no. 2, pp. 122-128, 2002, doi: 10.1046/j.1471-6712.2002.00069.x.

[12] J. F. Reckelhoff, "Gender differences in the regulation of blood pressure," Hypertension, vol. 37, no. 5, pp. 1199-1208, 2001, doi: 10.1161/01.HYP.37.5.1199.

[13] R. Mohammed, D. Omer, and N. K. Al-salihi, "Monitoring ( SWSHM )," 2017.

[14] B. Latré, B. Braem, I. Moerman, C. Blondia, and P. Demeester, "A survey on wireless body area networks," Wirel. Networks, vol. 17, no. 1, pp. 118, 2011, doi: 10.1007/s11276-010-0252-4.

[15] P. Puspitaningayu, A. Widodo, and E. Yundra, "The Emerging Wireless Body Area Network on Android Smartphones: A Review," IOP Conf. Ser. Mater. Sci. Eng., vol. 288, no. 1, pp. 0-5, 2018, doi: 10.1088/1757-899X/288/1/012116.

[16] M. Marjani et al., "Big IoT Data Analytics: Architecture, Opportunities, and Open Research Challenges," IEEE Access, vol. 5, no. c, pp. 5247-5261, 2017, doi: 10.1109/ACCESS.2017.2689040. 